\title{
Yenilenebilir Enerji Kaynağı Kurulum Gücü Minimize Katsayısının Belirlenmesi
}

\author{
Cihan Şahin ${ }^{1 *}$, Mevlüt Karaçor ${ }^{2}$, Harun Özbay ${ }^{3}$ \\ ${ }^{1}$ Bilecik Şeyh Edebali Üniversitesi, Meslek Yüksekokulu, Elektronik ve Otomasyon Bölümü, Bilecik, Türkiye (ORCID: 0000-0001-6430-7827) \\ ${ }^{2}$ Manisa Celal Bayar Üniversitesi, Hasan Ferdi Turgutlu Teknoloji Fakültesi, Mekatronik Mühendisliğ, Manisa, Türkiye (ORCID: 0000-0001-5408-9117) \\ ${ }^{1}$ Bilecik Şeyh Edebali Üniversitesi, Meslek Yüksekokulu, Elektrik ve Enerji $\quad$ Bölümü, Bilecik, Türkiye (ORCID: 0000-0003-1068-244X)
}

(İlk Geliş Tarihi 14 Şubat 2019 ve Kabul Tarihi 13 Mart 2019)

(DOI: 10.31590/ejosat.526918)

ATIF/REFERENCE: Şahin, C., Karaçor, M. \& Özbay, H (2019). Yenilenebilir Enerji Kaynağı Kurulum Gücü Minimize Katsayısının Belirlenmesi. Avrupa Bilim ve Teknoloji Dergisi, (15), 404-411.

\section{$\ddot{O} \mathbf{z}$}

Dünyamız gün geçtikçe daha fazla enerji ihtiyacı ile karşı karşıya kalmaktadır. İhtiyaç duyduğu enerji miktarını büyük oranda fosil yakıtlardan elde etmektedir. Günümüz dünyasında Fosil yakıtlarının fiyatlarında önlenemeyen artı̧̧lar, gelecekte tükenme olasıllğı ve çevreye bırakmış olduğu kalıcı etkiler sebebiyle son yıllarda alternatif enerji kaynaklarına büyük bir yönelim başlamıştır. Bu alanda Güneş enerjisi, Rüzgar enerjisi, Dalga enerjisi, Gelgit enerjisi vb. alternatif enerji kaynaklarına örnek olarak verilebilir. Özellikle Güneş ve Rüzgar enerjisi dünyada ve ülkemizde alternatif enerji kaynaklarının kullanımında en önde gelen enerji türleridir. Ülkemizin farklı bölgelerinde kurulan değişik büyüklükte rüzgar ve güneş çiftliklerinin sayılarında da artışlar görülmektedir. Bunlarla birlikte gelişen dünyamızda yaşanan teknolojik gelişmeler, birçok alanda olduğu gibi enerji sektörüne de doğrudan katk1 sağlamaktadır. Gelişen teknolojilerle birlikte alternatif enerjilerin verimli bir şekilde kullanılması bu enerjilere olan ilgiyi de arttırmaktadır. Özellikle otomasyon ve kontrol dünyasında yaşanan teknolojik gelişmeler, birçok alanda kolaylıkları da beraberinde getirmiştir. Endüstri 4.0'ın doğması otomasyon ve kontrol dünyasını farklı bir boyuta ve bir çok alanda vazgeçilmezler noktasına getirmiş̧ir. PLC, SCADA, DCS sistemlerinin yenilenebilir enerjiler alanında da kullanılması enerji yönetiminin verimliliği açısından oldukça önemlidir. Elde edilen alternatif enerji, otomasyon sistemleri sayesinde daha verimli ve tasarruflu kullanılabilmektedir. Bu çalışmada, alternatif enerji kaynağı ve otomasyon sistemlerinin birbirine entegrasyonuyla birlikte kurulum maliyet oranlarının düşürülmesi hedeflenmiştir. Çalışma için alternatif enerji kaynaklarından güneş enerjisi tercih edilmiş, laboratuvar ortamında 320 W'llk prototip test sistemi kurularak deneysel çalışma gerçekleştirilmiştir. Gerçekleştirilen bu çalışma sayesinde ihtiyaç duyulduğu düşünülen enerji miktarından \% 40 daha az enerjiye ihtiyaç olduğu gözlemlenmiş, güneş enerjisi kurulum gücü için bir katsayı oluşturulmuştur. Bununla birlikte, enerjinin verimli ve kontrollü bir şekilde kullanılması sağlanarak, hesaplanan kurulum gücünün düşürüldüğü görülmüştür. Elde edilen sonuç diğer alternatif enerji kaynakları içinde kullanılabilmektedir.

\section{Determination of the Minimization Coefficient of Renewable Energy Source Installation Power}

\begin{abstract}
The world is confronted with more energy needs day by day. The energy that needed is largely derived from fossil fuels. In today's world, a great tendency towards alternative energy sources has started in recent years due to unpredictable price increases of fossil fuels, the possibility of extinction in the future and the lasting effects on the environment. In this area, solar energy, wind energy,
\end{abstract}

${ }^{*}$ Sorumlu Yazar: Bilecik Şeyh Edebali Üniversitesi, Meslek Yüksekokulu, Elektronik ve Otomasyon Bölümü, Bilecik, Türkiye, ORCID: 0000-00016430-7827, cihan.sahin@bilecik.edu.tr 
wave energy, tidal energy etc. are examples of alternative energy sources. In particularly Solar and Wind energy are the leading energy types in the use of alternative energy sources in the world and in our country. There are also increases in the number of different sizes of wind and solar farms established in different regions of our country. Together with these, technological developments in developing world directly contribute to the energy sector as in many other areas. With developing technologies, the efficient use of alternative energies increases the interest in these energies. Technological developments especially in the world of automation and control have brought convenience in many areas. The emergence of Industry 4.0 brought the world of automation and control to a different dimension and to the point of indispensable in many areas. The use of PLC, SCADA, DCS systems in the field of renewable energies is also very important for the efficiency of energy management. The alternative energy obtained can be used more efficiently and economically owing to the automation systems. In this study, it is aimed to reduce the installation cost ratios with the integration of alternative energy source and automation systems. Solar energy is preferred for alternative energy sources and a 320 $\mathrm{W}$ prototype test system has been installed and experimental study was carried out in the laboratory. Owing to this study, it was observed the energy amount that needed is \%40 less than the amount of expected energy needed and the coefficient was created for solar power installation power. In addition, it has been observed that the calculated installation power is reduced by ensuring that the energy is used in an efficient and controlled. The result obtained can be used for other alternative energy sources.

Keywords: Solar energy, PLC, Automation.

\section{Giriş}

Teknolojik yenilikler, insanoğlunun hayatının her noktasına etki etmektedir. Otomotiv, sağlık, alışveriş vb. birçok değişik sektörde geliştirilen modern cihazlar insanoğlunun memnuniyet noktasını daha yükseklere taşımaktadır. İnsanoğlunun hayatın her noktasında maksimum konfor istemesi nedeniyle enerji ihtiyacını da günden güne arttırmaktadır. Otomotiv sektörü, yakıt performansı yüksek araçlar üretmesine rağmen fosil yakıt rezervlerin her gecen gün daha da azalmasından dolayı elektrikli araç çalışmalarına büyük önem vermektedirler. Üreticiler araç yakıt tipini değiştirmekle kalmayıp, aynı zamanda verimli şekilde enerji tasarrufu yapmak için çalışmalara devam etmektedirler. Benzer şekilde sağlık sektöründen, kişisel kullanıma kadar tüm cihazlarda enerji verimliliği ön plana çıkmaktadır. Tüm bu çalışmalara rağmen enerji kaynaklarının yetersizliği, insanoğlunu alternatif enerji kaynaklarına yönlendirmiştir. Güneş Enerjisi, Rüzgar Enerjisi, Jeotermal Enerji, Biyokütle Enerjisi, Hidrojen Enerjisi ve Dalga Enerjisi alternatif enerji kaynakları olarak sıralanabilir. Bunlar içerisinde en yaygın olanı ve en ön plana çıkanı hiç kuşkusuzdur ki, Güneş ve Rüzgar enerjisidir. Her iki alternatif enerji de ülkemizde yaygın olarak kullanılmaktadır. Yapılan çalışmada güneş enerjisi tercih edilmiştir.

Gelişen dünyamızda enerji alanında alternatif enerji kaynaklarına doğru bir yönelim olmasının paralelinde, tüm dünyayı etkileyecek önemli bir devrim de Endüstri 4.0 dır. Buhar sistemlerinin mekanik sistemlere entegre edilmesi birinci sanayi devrimini gerçekleştirmiştir. 1760-1830 yılları arasındaki dönemleri etkileyen birinci sanayi devrimi dokuma tezgahları üzerinde etkisini göstermiştir. Odunun yerine maden kömürünün ve buharın kullanılmasıyla hareket gücü arttırılmış, buna bağlı olarak makineleşmeyi başlatmış ve üretim evlerden fabrikalara taşınmıştır (Eldem, 2017).

İkinci sanayi devrimi ise 1870 yılında başlamış 1989 doğu bloğunun çöküşüyle biten bir süreçtir. Bu dönemde petrolün endüstri ve ulaşımdaki etkinliği keşfedilmiş, petrol tabanlı içten yanmalı motorların üretimini tetiklemiştir (Eldem, 2017; Bulut ve Akçaçı, 2017).Üretimde elektrik enerjisi sayesinde seri üretim başlamıştır.

Üçüncü sanayi devrimi, elektronik ve bilgi teknolojilerinde yaşanan gelişmelerle başlamıştır. Özellikle Telekomünikasyon teknolojileri, üçüncü sanayi devrimiyle birlikte daha güçlü bir konuma gelmiştir. Programlanabilir mantıksal denetleyici (PLC)'lerin gelişmesi sonucunda üretimde otomasyon ileri aşamalara taşınmaya başlamıştır (Eldem, 1994; Kılıç ve Alkan, 2018)

Günümüzde ise 2011 yılında Hannover fuarında ilk olarak gündeme gelen, Alman hükümeti tarafindan 2012 y1lında özel bir çalışma grubuna hazırlatılan, 2013 yılında sonuç raporuyla açıklanan Endüstri 4.0 olarak adlandırılan sanayi devrimine geçiş yapılmaktadır (Kılıç ve Alkan, 2018). Şekil 1'de endüstrileşme aşamaları görülmektedir (Eldem, 2017).

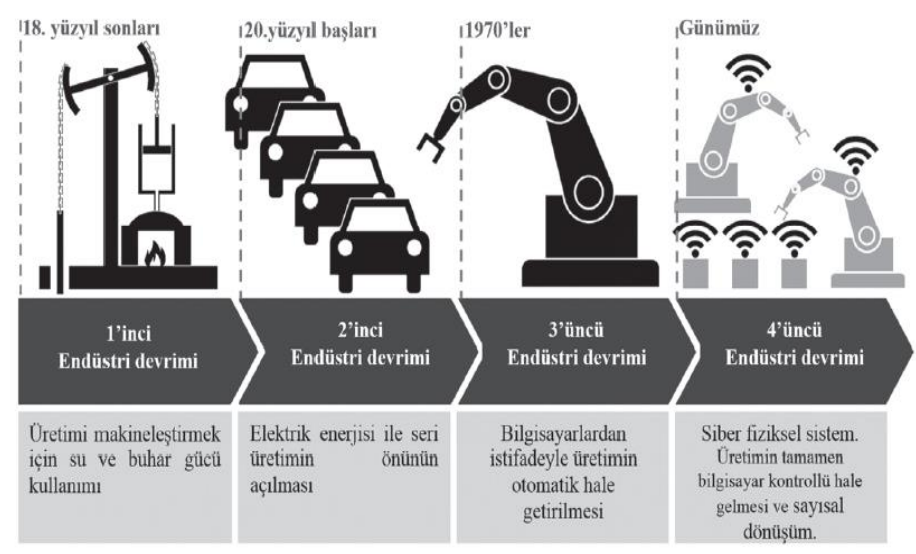

Şekil 1. Endüstrileşme aşamaları (Eldem, 2017) 
Endüstri 4.0 devriminin gerçekleştirilmesiyle birlikte otomasyon sistemlerinin kullanılmadığı bir yapı düşünülmez hale gelmiştir. Tüm dünyanın birbirine entegrasyonu, beraberinde enerji verimliliği, üretim maliyet verimliliği vb. birçok noktada avantajları da beraberinde getirmektedir. Gerçekleşen Endüstri 4.0 devriminde sahada bir çok cihaz aktif olarak kullanılmasına rağmen, PLC sistemleri büyük bir öneme sahip olmaya devam etmektedir. Ayrıca, Endüstri 4.0 devriminde güneş enerjisi gibi yenilenebilir enerji kaynaklarının kullanılması da enerji yönetimi ve verimlilik açısından oldukça önemli bir yere sahiptir.

Gerçekleştirilen çalışmada; güneş enerjisi sisteminin kurulu gücünün tespit edilmesinde kullanılabilecek, verimlilik ile ilgili yeni bir parametre geliştirilmiştir. Bu parametre; üretim veya meskenin ihtiyacı olan gerçek verimli gücün tespitinde kullanarak, kurulum gücünün ve dolayısıyla maliyetinin düşürülebileceği öngörülmüştür. Tesisin veya meskenin salt tükettiği enerji miktarına bakılarak ihtiyaç duyulan gücün belirlenmemesi, bunun yerine enerji verimliliği ile ilgili iyileştirmeler göz önünde bulundurularak belirlenmelidir. Mesken veya tesis enerji ihtiyaçlarının karşılanmasında yenilenebilir enerji ciddi bir alternatif haline geleceği öngörüknektedir. Gerçekleştirilen otomasyon sistemi sayesinde işletmeler; alternatif enerji kullanımında verimli bir enerji yönetimi gerçekleştirmenin yanında, kurulum maliyetinden de tasarruf etmektedirler. Bunlarla birlikte, gerçekleştirilmiş otomasyon sistemleri sayesinde Endüstri 4.0’ın genel felsefesi ile diğer cihazlarında verimliliği gerçekleştirilebilmektedir.

\section{Güneş Enerjisi}

Güneş enerjisi; insanlığın varoluşundan günümüze kadar sürekli faydalanılmak istenen enerji türlerinden biridir. Tarih boyunca insanoğlu, Güneş’ten çeşitli şekillerde faydalanmıştır. İnsanların ilk çağlarda zaman kavramını çözmek için kullandıkları güneş, zamanla ısınmadan elektrik enerjisi üretimine kadar çeşitli şekillerde fayda sağlamıştır. Özellikle güneşin yoğun olduğu bölgelerde geçmişten günümüze bunların izleri daha da net görülmektedir.

Günümüzde uygulama türlerinden biri de güneş pilleri kullanarak yapılan fotovoltaik uygulamalardır. Güneş pilleri, üzerine düşen ışınımı direk olarak elektrik enerjisine çevirirler. doğru gerilim üreten bu piller seri veya paralel bağlanarak, ürettikleri akım ve gerilim değerleri yükseltilebilmektedir. Üretilen enerji akülerde depolanabilmekte veya doğrudan inverter üzerinden şebekede kullanılabilmektedir (Karafil ve Özbay, 2018; Karamanav, 2007). Şekil 2'de birbirine seri olarak bağlanmış üç adet güneş pili akım gerilim grafiği ve şeması görülmektedir (Grozdev, 2010). Şekil 3'de birbirine paralel olarak bağlanmış üç adet güneş pili akım gerilim grafiği ve şeması görülmektedir (Grozdev, 2010).

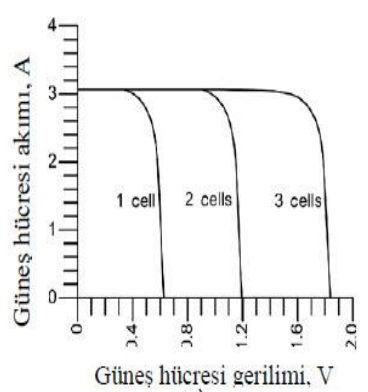

a)

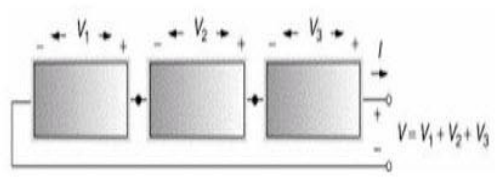

b)

Şekil 2. (a) I-V grafiği (b) Bağlantı Şeması (Grozdev, 2010)

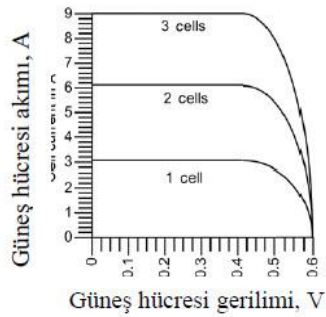

a)

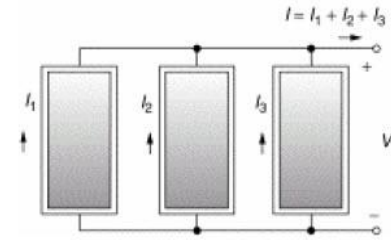

b)

Şekil 3. (a) I-V grafiği (b) Bağlantı Şeması (Grozdev, 2010)

Fotovoltaik güneş teknolojileri genel elektrik şebekesiyle ilişkisine göre; ada şeklinde çalışan yani şebekeden bağımsız olarak çalışan sistem ve şebekeye bağlı çalışan sistem olarak ikiye ayrılmaktadır (Saner, 2015). Ada tipi bağımsız çalışan fotovoltaik sistemler şebekeden uzak bölgelerde tercih edilerek bölgenin elektrik enerji ihtiyacı için kullanılmaktadırlar. Bu sistemde ihtiyaç kadar enerji üretilir ve ek bir ünitede enerji depolaması yapılır (Durusu ve Erduman, 2018; Saner, 2015). Şebekeye bağlı çalışan fotovoltaik sistemlerde üretilen enerji şebekeye aktarılmaktadır. Yüksek güçteki enerji santralleri ya da güneş çiftlikleri olarak da adlandırılan sistemler, genel elektrik enerjisi için üretim yapmaktadır (Saner, 2015). Güneş teknolojilerinin gelişmesi, kullanımın yaygınlaşması, otomasyon dünyasının bu teknolojilere entegrasyonunu kaçınılmaz kılmışıı. Süreç denetiminin tarihsel gelişimi akademik olarak birçok çalışmaya da ilham kaynağı olmuştur. Son yıllarda alternatif enerjini kaynaklarına olan ilgi otomasyon sistemleriyle entegre olarak yeni akademik çalışmalar da sunmuştur. 
Pasc ve arkadaşlarının 2016 yılında yaptıkları çalışma da, solar fotovoltaik MPPT (Maximum Power Point Tracker) kontrolörünün similasyonu gerçekleştirilmiştir. CitectSCADA gerçekleştirilen uygulamada, verilen lokasyondaki solar radyosyan ve yük eğrisi için matematiksel fonksiyon tabanlı MPPT similasyonu gerçekleştirilmiştir (Pasc ve Dumitru, 2016). Dumutri ve arkadaşlarının 2012 yılında yaptıkları çalışmada, yenilenebilir enerji yönetimi için SCADA tabanlı yazılım gerçekleştirilmiştir. Sahadan PLC, RTU gibi yapılardan alınan bilgiler lokal noktalarda ve uzak noktalarda gözlemleme ve denetlenebileceğini anlatmışlardır (Dimitru ve Gligor, 2012). Moghavvemi ve arkadaşlarının 2013 yılında yaptıkları çalışmada, uzak bölgelere yerleştirilmiş uzaktan kontrolü sağlayan FM transmiterlar için PV/dieselhybrid sistemlerin geliştirilmesi ve optimizasyonu gerçekleştirilmiştir (Moghavvemi ve ark. 2013). Shariff ve arkadaşlarının 2015 yılında yapmış oldukları çalışmada şebeke bağlantılı Fotovoltaik sistemin online görüntülenmesi için düşük güç tüketimi ve düşük data transfer oranına sahip kablosuz haberleşme sistemi olan Zigbee tabanlı data toplama sistemi yapılmıştır. Farklı noktalara yerleştirilen data toplama merkezleriyle modüllere ait veriler toplanmıştır (Shariff ve ark. 2015). Alphonsus ve arkadaşlarının 2016 yılında yaptığı çalışma PLC'lerin yenilenebilir enerji alanında uygulamalarına dönük bir incelemedir. PLC'ler tanıtılmış, Güneş, Rüzgar, Fotovoltaik gibi yenilebilir enerji alanlarında kullanımlarına örnekler verilmiştir (Alphonsus ve Abdullah, 2016). Guozhen ve arkadaşlarının 2009 yılında yapmış oldukları çalışma fotovoltaik güç santrallerinde SCADA sistemleri haberleşmeleri güvenirlik için çözümler sunulmuştur. Bunun için Güvenlik erişim kontrolü stratejisi ve yedekleme mekanizmasından oluşan iki etkili çözüm sunulmuştur (Guozhen ve ark. 2009). Georgescu'nun 2014 yilında yapmış olduğu çalışma fotovoltaik tarlalar için oluşturulan sevk merkezleri için SCADA yazılımı gerçekleştirilmiştir (Georgescu, 2014). Zapata ve arkadaşlarının 2016 yılında yapmış oldukları çalışmada solar fotovoltaik yapının IEC 61850 and ISA S101 uluslararası standartları ve OPC, Modbus TCP haberleşme protokolleri kullanılarak SCADA sistemi gerçekleştirilmiştir (Zapata ve ark. 2016). Zhaoxia ve arkadaşları tarafından 2017 yılında yapılan çalışmada fotovoltaik, rüzgar gülü ve bataryalardan oluşan sistemin SCADA tabanlı denetimi gerçekleştirilmiştir (Zhaoxia ve ark. 2017)

\section{Malzeme ve Yöntem}

Çalışmanın gerçekleştirilebilmesi amacıyla, laboratuvar ortamında aydınlatma ve havalandırma sisteminin prototipi gerçekleştirilmiştir. Prototip temel olarak üç gruba ayrılmaktadır. Birinci grup güneş enerjisinin sisteme entegrasyonu için; 2 adet polikristal 160 Watt güneş paneli, 1 adet 1kVA inverter, 1 adet 12 V 100 Ah jel akü ve 100 Watt IP66 Led projektörden oluşmaktadır. İkinci grup otomasyon grubu olup, temel olarak 1 adet 1şı ş̧iddeti ölçüm transmiteri, 1 adet S7 1200 PLC, 2 adet PAC3200 enerji analizörü, 1 adet Sinamics G120C motor sürücü ve akımların analizörler tarafindan ölçülmesi için 5/1 oranlı akım trafolarından oluşmaktadır. Kullanılan güneş panelleri ve inverterin özellikleri sırasıyla Tablo 1 ve Tablo 2 de verilmiştir.

Tablo 2. PV modüllerinin özellikleri

\begin{tabular}{|c|c|}
\hline Özellikler & Değer \\
\hline MPP Gerilimi & $18.8 \mathrm{~V}$ \\
\hline MPP Akımı & $8.53 \mathrm{~A}$ \\
\hline Açı Devre Gerilimi & $23.2 \mathrm{~V}$ \\
\hline Kısa Devre Akımı & $9.12 \mathrm{~A}$ \\
\hline Güç Toleransı & $\pm 3 \%$ \\
\hline
\end{tabular}

Tablo 1. Inverterin Özellikleri

\begin{tabular}{|l|c|c|}
\hline Mode & Özellik & Değer \\
\hline \multirow{4}{*}{ Inverter } & Anma Gücü & $1 \mathrm{kVA} / 1 \mathrm{~kW}$ \\
\cline { 2 - 3 } & DC Giriş & $12 \mathrm{VDC}$ \\
\cline { 2 - 3 } & AC Çıkış & $230 \mathrm{VAC} \pm 5 \%$ \\
\hline \multirow{3}{*}{ AC } & AC Giriş & $230 \mathrm{VAC} / 50 \mathrm{~Hz}$ \\
\hline \multirow{4}{*}{ Solar } & DC Çıkış & $12 \mathrm{VDC}$ \\
\cline { 2 - 3 } & Anma Gücü & $1000 \mathrm{~W}$ \\
\cline { 2 - 3 } & Sistem Gerilimi & $12 \mathrm{VDC}$ \\
\cline { 2 - 3 } & Oper. Gerilimi & $15-18 \mathrm{VDC}$ \\
\cline { 2 - 3 } & Max. Sol. Gerilimi & $55 \mathrm{VDC}$ \\
\hline
\end{tabular}

Üçüncü grup aydınlatma ve havalandırma sisteminde oluşmaktadır. Aydınlatma sistemi prototipi için, 550 Watt'llk akkor flamanlı ampul seti kullanılmıştır. Bu sayede gerçek bir işletme ortamında harcanan aydınlatma gücüne denk enerji sarfiyatı sağlanması hedeflenmiş̧tir. Benzer şekilde havalandırma sistemlerinin prototipi amacıyla 3 faz $1,1 \mathrm{~kW}$ 'lık asenkron motor deney seti kullanılmıştır. Asenkron motor’a yabancı uyartımlı generatör akuple edilmiş, genaratör çıkışlarına omik yük bağlanarak havalandırma enerji sarfiyatı benzetişimi yapılmıştır. Şekil 4'de prototipi gerçekleştirilen işletme dizaynı gözükmektedir. 


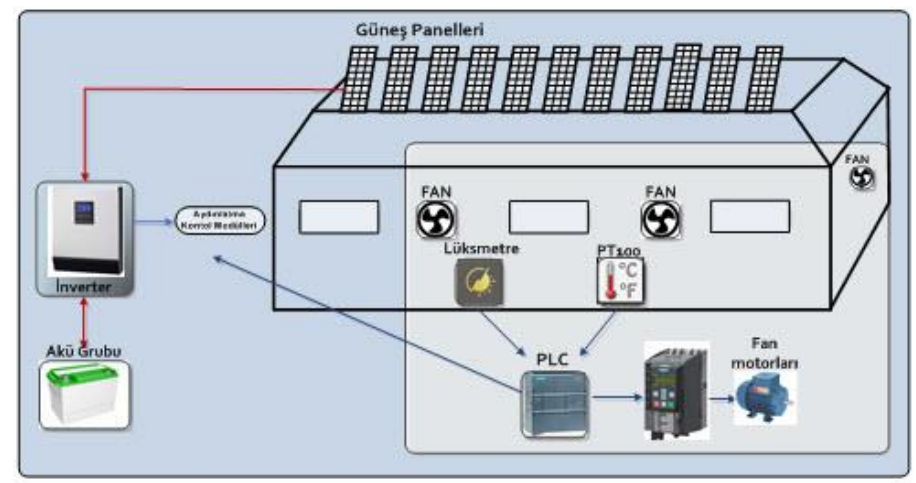

Şekil 4. Prototipi gerçekleştirilen işletme dizaynı

\subsection{Sistemin İhtiyaç Duyduğu Standart Enerjinin Belirlenmesi}

Prototipi gerçekleştirilen sistemde enerji sarfiyatı yapan iki birim bulunmaktadır. Bunların birincisi aydınlatma grubu, ikincisi motor gruplarıdır. Her iki birimin enerji sarfiyatını ölçmek amacıyla PAC enerji analizörleri kullanılmıştır. Yüklerin çektiği akım değerleri akım trafosu üzerinden ölçülmüştür. Otomasyon sisteminin dahil edilmediği ham durumda sistemin standart durumunda ihtiyaç duyduğu enerji belirlenmiştir. Şekil 5 'te sistemin ham durumuna ait ölçüm yapısı görülmektedir.

Prototip sistemin enerji tüketimi PAC3200 enerji analizörleri üzerinden saatlik ölçülmüştür. Tablo 3’te aydınlatma grubu enerji tüketim ölçümleri, Tablo 4’te motor grubu enerji tüketim ölçümleri görülmektedir.

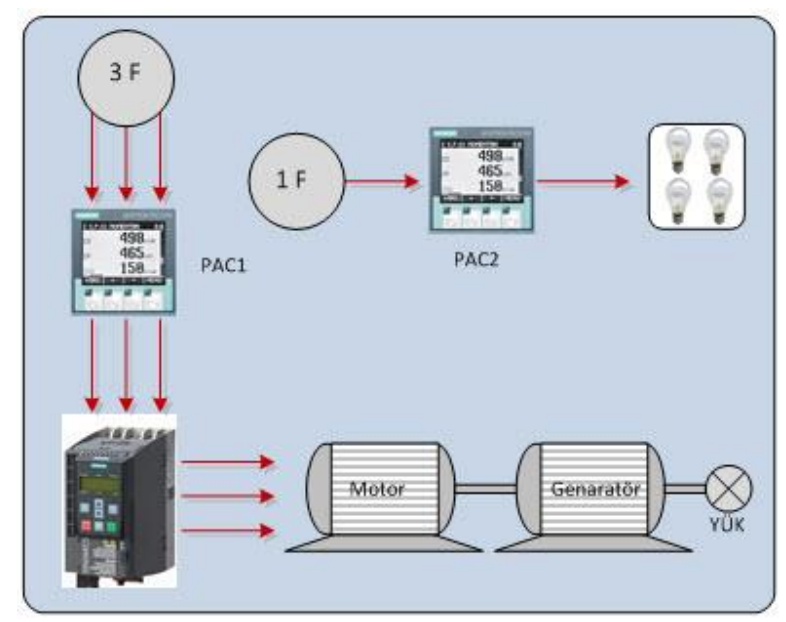

Şekil 5. Sistemim enerji tüketim ölçüm şeması

Tablo 3. Aydınlatma grubu saatlik enerji tüketimi

\begin{tabular}{|c|c|}
\hline $\mathrm{V}_{\text {ph-ph ANLIK }}$ & $225 \mathrm{~V}$ \\
\hline Görünen Enerji & $0,55 \mathrm{kVAh}$ \\
\hline Aktif Enerji & $0,55 \mathrm{kWh}$ \\
\hline
\end{tabular}

Tablo 4. Motor grubu saatlik enerji tüketimi

\begin{tabular}{|c|c|}
\hline $\mathrm{V}_{\text {ph-ph ANLIK -L12 }}$ & $397 \mathrm{~V}$ \\
\hline $\mathrm{V}_{\text {ph-ph ANLIK -L23 }}$ & $394 \mathrm{~V}$ \\
\hline $\mathrm{V}_{\text {ph-ph ANLIK -L31 }}$ & $396 \mathrm{~V}$ \\
\hline Aktif Enerji & $0,87 \mathrm{kWh}$ \\
\hline Görünen Enerji & $1,76 \mathrm{kVAh}$ \\
\hline
\end{tabular}

\subsection{Sistemin İhtiyaç Duyduğu Alternatif Enerji Kaynağının Kurulması}


Prototipi gerçekleştirilen işletme de aydınlatma sisteminin güç tüketimi $0,55 \mathrm{kWh}$, Motor grubu güç tüketimi $0,87 \mathrm{kWh}$ olarak ölçülmüştür. Tasarımı prototiplenen işletme ortamında aydınlatma grubu güneş enerjisinden elde edilen enerji ile beslenmektedir. Buna karşın motor grubu şebekeden beslenmektedir. Aydınlatma grubunun saatlik $0,55 \mathrm{kWh}$ enerji tükettiği düşünüldüğünde, en az bu gücü karşılayacak güneş panellerinin kurulması gerekmektedir. Geliştirilen sistem; standart sisteme güneş panelleri, 1ş1k ölçüm sensörü, PLC entegre edilerek elde edilmiştir. Ayrıca sabit olarak enerji tüketimi gerçekleştiren motor fan grubu da kurulmuş olan PLC tabanlı otomasyon sistemine entegre edilmiştir. Standart sistemde; aydınlatma grubu hiçbir otomasyon ve kontrol sistemine tabi değildir. Bu sebeple enerji tüketimi sürekli olarak sabit olmaktadır. Geliştirilen sistemde aydınlatma grubu ortam ışı miktarına bağlı olarak otomasyon tabanlı kontrol edilmiştir. Ortamdaki 1şık miktarı 1şık ölçüm transmiteri tarafında ölçülerek PLC ortamına analog değer olarak aktarılmaktadır. PLC ölçülen analog değere bağlı olarak dijital çıkışlara bağlı olan röle grubunu kontrol etmektedir. Röle grubu dört farklı aydınlanma bölgesi için ayrı olarak tasarlanmıştır. Bu sayede ortam 1şık miktarına göre hangi grupların aktif veya pasif olacağı belirlenmektedir. Diğer bir ifadeyle sürekli sabit enerji sarfiyatı yerine ihtiyaç oranında enerji tüketimi gerçekleşmektedir. PLC sistemi kullanıcıya geniş bir alanı denetleme ve kontrol olanağı sunmaktadır. Gerçekleştirilen PLC tabanlı otomasyon sistemine motor grubu da entegre edilmiştir. PLC S7-1200 ve motor sürücü Sinamics G120C eternet protokolü üzerinden haberleştirilmiştir. Entegre edilen motor grubu ortam ısısına bağlı olarak PLC üzerinden denetlenmiş, bu sayede fan grubu enerji sarfiyatında da ek bir enerji verimliliği sağlanmıştır. Motor grubundan elde edilen enerji verimliği sayesinde işletme giderlerinden kar elde edilerek, güneş enerjisi tabanlı kurulan otomasyon sisteminin amortisman giderlerine katkı sağlanmıştır. Şekil 6'da geliştirilen otomasyon tabanlı, güneş enerjisi beslemeli aydınlatmaya sahip işletme ölçüm yapısı görülmektedir.

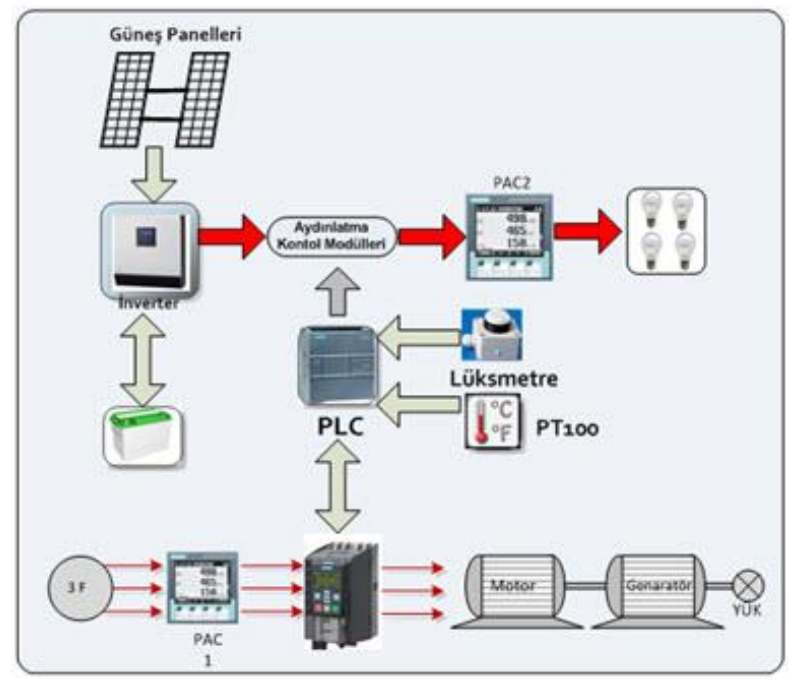

Şekil 6. Geliştirilen otomasyon tabanlı, güneş enerjisi beslemeli aydınlatmaya sahip işletme ölçüm yapısı

Şekil 6'de geliştirilen sistemde aydınlatma grubu tamamıyla güneş panellerinden elde edilen enerjiden beslenmektedir. Standart sisteme PLC tabanlı otomasyon sisteminin entegre edilmesi sayesinde hem aydınlatma hemde motor enerji sarfiyatında güç tüketimi azalmıştır. Tablo 5'te motor kontrol biriminin otomasyon tabanlı güç tüketimi, Tablo 6'da aydınlatma sisteminin otomasyon tabanlı güç tüketim ölçümleri görülmektedir. Otomasyon tabanlı gerçekleştirilen prototip denetimli işletmede aydınlatma sisteminin enerji tüketimi $0,33 \mathrm{kWh}$, Motor grubu enerji tüketimi $0,48 \mathrm{kWh}$ olarak ölçülmüştür. Şekil 7 'de otomasyon panosu, güneş panalleri ve motor deney seti görülmektedir.

Tablo 5. Motor grubu saatlik enerji tüketimi

\begin{tabular}{|c|c|}
\hline $\mathrm{V}_{\text {ph-ph ANLIK -L12 }}$ & $397 \mathrm{~V}$ \\
\hline $\mathrm{V}_{\text {ph-ph ANLIK -L23 }}$ & $394 \mathrm{~V}$ \\
\hline $\mathrm{V}_{\text {ph-ph ANLIK -L31 }}$ & $396 \mathrm{~V}$ \\
\hline Aktif Enerji & $0,48 \mathrm{kWh}$ \\
\hline Görünen enerji & $0,99 \mathrm{kVAh}$ \\
\hline
\end{tabular}

Tablo 6. Aydınlatma sisteminin otomasyon tabanlı güç tüketimi

\begin{tabular}{|c|c|}
\hline $\mathrm{V}_{\text {ph-ph ANLIK }}$ & $225 \mathrm{~V}$ \\
\hline Görünen Enerji & $0,33 \mathrm{kVAh}$ \\
\hline Aktif Enerji & $0,33 \mathrm{kWh}$ \\
\hline
\end{tabular}




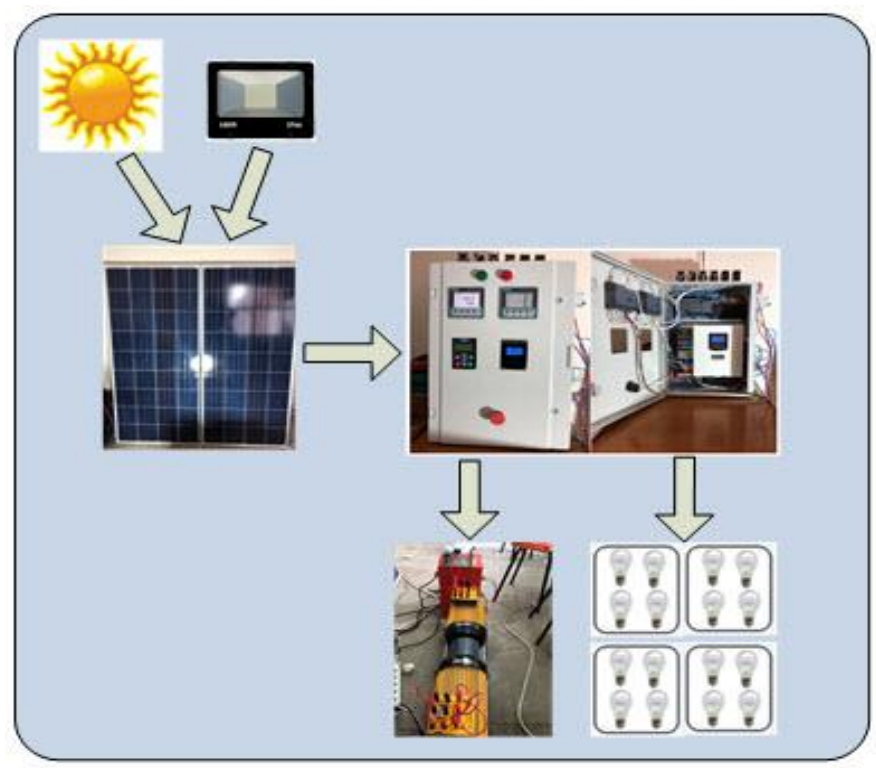

Şekil 7. Uygulama panosu, Güneş panalleri ve motor deney seti görülmektedir

\section{Bulgular Ve Tartışma}

Yapılan ölçümlerde, otomasyon sisteminin entegre edilmesi sayesinde enerji tüketiminin her iki birimde de azaldığı görülmüştür. Aydınlatma sisteminde enerji sarfiyatı $0,55 \mathrm{kWh}$ tüketimden $0,33 \mathrm{kWh}$ tüketime düştüğü görülmüştür. Motor kontrol sisteminde 0,87 kWh tüketimden $0,48 \mathrm{kWh}$ tüketime düştüğü görülmüştür. Fotovoltaik sistem kurularak, aydınlatma sisteminin alternatif enerjiyle beslenmesiyle, entegre edilen otomasyon sistemi her iki birime de katkı sağlamıştır. Otomasyon sistemi aydınlatma gruplarını ortam 1şık şiddetine bağlı olarak devreye almıştır. Bu sayede sabit tüketim yerine ortam aydınlığına bağlı tüketim gerçekleştirilmiştir. Aydınlatma sisteminin standart güç tüketimine bakıldığında, kurulacak Fotovoltaik sistemin en az 0,55 kWh olması gerekmektedir. Fakat otomasyon sistemi sayesinde $0,33 \mathrm{kWh}$ değerine düşmektedir. Bu durumda $\% 40$ oranında kazanç olmaktadır. Kurulan sistem için istenen güç miktarı olması gerekenden $\% 40$ daha fazladır. Elde edilen enerjinin otomasyon sistemi sayesinde tasarruflu ve verimli kullanılması sayesinde kurulum gücü standart belirlenenden güçden daha düşük olarak gerçekleşebilmektedir. Bu durumdan dolayı otomasyon tabanlı bir fotovoltaik sistem kurulurken standart güç tüketiminin belli bir katsayıyla çarpılıp elde edilen güç miktarına göre kurulması, kurulum maliyetlerini azaltacaktır. Bu noktada kullanıcı otomasyon denetimli alternatif enerji kaynağı kurulum gücünü belirleyebilmesi için bir katsayıya ihtiyaç duymaktadır. Kazanç katsayısı, otomasyon tabanlı enerji tüketiminin, standart enerji tüketimine oranı şeklinde bulunabilir. Kazanç katsayısı "K” olarak, Otomasyon tabanlı enerji tüketimi "OTET", standart enerji tüketimi "SET” olarak adlandırılırsa, Eşt. 1'de gösterildiği şekilde yazılabilir.

$$
K=O T E T / S E T
$$

Kurulan sistemin SET değeri Tablo 3'ten 0,55 kW, OTET değeri Tablo 5'ten 0,33 kW olarak alınıp denklem 1 'de yerine konduğunda kazanç katsayısı " $\mathrm{K}$ ” ‘ 0,6 ’ olarak bulunmuştur.

\section{Sonuç}

Günümüzde Alternatif enerjiye artan ilgiyle beraber alternatif enerji kaynaklarının verimli kullanılması ve elde edilmesi için gereken kurulum maliyetinin minimumlarda olması ayrı bir hedef olmuştur. Bu noktada otomasyon sistemleri büyük rol oynamaktadır. Özellikle endüstri 4.0'ın doğmasıyla günümüz dünyasında otomasyon sistemlerinin olmadığı bir yapı eksik olarak düşünülmektedir. Yapılan bu çalışmada kurulacak olan fotovoltaik sistemin, kurulum maliyetlerinin azalması için ' $\mathrm{K}$ ' katsayısı elde edilmeye çalışılmıştır. Standart olarak kurulacak sistemin gücü doğrudan ihtiyaç olan güç miktarıdır. Fakat enerjinin verimli ve kontrollü bir şekilde kullanılmasıyla ihtiyaç olarak hesap edilen güç miktarı azaltılmaktadır. Prototip olarak kurulan sistemde aydınlatma denetimi gerçekleştirilmiş, sistem her iki şekilde test edilerek denetimli bir yapıyla harcanan enerjinin düştüğü görülmüştür. Bu durumda kurulum gücü de standart belirlenenden aşağı olabileceği belirlenmiştir. Bunu belirlemek için "K" katsayısı 0.6 olarak elde edilmiştir. Bu katsayı sayesinde tüketilen güce göre değil, otomasyon sistemleri sonucu verimliliği arttırılmış enerji tüketimine göre fotovoltaik sistemin kurulması önerilmiştir. Ayrıca kurulacak otomasyon sistemi diğer birimlere de entegre edilmiş bunun sonucunda enerji tüketim verimliliği \%40 yükselmektedir. Bu sayede otomasyon sisteminin kurulum maliyeti de kendini zamanla amorti etmektedir.

TEŞEKKÜR: Bu çalışma Bilecik Şeyh Edebali Üniversitesi Bilimsel Araştırma Projeleri tarafından desteklenmiştir (Proje no: 2017-01.BŞEÜ.11-01). 


\section{Kaynakça}

Alphonsus, E.R., \& Abdullah, M.O. (2016). A review on the applications of programmable logic controllers (PLCs). Renewable and Sustainable Energy Reviews, 60, 1185-1205.

Bulut, E., \& Akçacı, T. (2017). Endüstri 4.0 ve inovasyon göstergeleri kapsamında Türkiye analizi. ASSAM Uluslararası Hakemli Dergi, 4(7), 50-72.

Dimitru, C.D., \& A. Gligor, A. (2012). SCADA based software for renewable energy management system, Procedia Economics and Finance, 3, 262-267.

Durusu, A., \& Erduman, A. (2018). An Improved Methodology to Design Large-Scale Photovoltaic Power Plant, Journal of Solar Energy Engineering 140(1), 011007.

Eldem, M.O. (2017) Endüstri 4.0, TMMOB EMO Ankara Şubesi Haber Bülteni.

Georgescu, V.C. (2014). SCADA Software used in Dispatch Centre for Photovoltaic Parks, 6th Edition Electronics, Computers and Artificial Intelligence, Bucharest, Romania, 1-4.

Guozhen, H., Tao, C., Changsong, C. \& Shanxu, D. (2009). Solutions for SCADA system Communication Reliability in Photovoltaic Power Plants, IEEE 6th International Power Electronics and Motion Control Conference, Wuhan, China, 2482- 2485.

Grozdev, M. (2010). Alternatif enerji kaynakları, Yüksek lisans Tezi, Elektrik-Elektronik Mühendisliği Anabilim Dalı, İstanbul Üniversitesi, İstanbul, Türkiye.

Karafil, A., \& Özbay H. (2018). Design of Stand-Alone PV System on a Farm House in Bilecik City, Turkey, El-Cezeri Journal of Science and Engineering, 5(3), 909-916.

Karamanav, M. (2007). Güneş enerjisi ve güneş pilleri, Yüksek lisans Tezi, Elektronik-Bilgisayar Eğitimi Anabilim Dalı, Sakarya Üniversitesi, Sakarya, Türkiye.

Kılıç, S., \& Alkan, R.M. (2018). Dördüncü sanayi devrimi Endüstri 4.0: Dünya ve Türkiye değerlendirmeleri, Girişimcilik İnovasyon ve Pazarlama Araştırmaları Dergisi, 2(3), 29-49.

Moghavvemi, M., Ismail, M.S., Murali, B., Yang, S.S., Attaran, A., \& Moghavvemi, S. (2013). Development and optimization of a PV/diesel hybrid supply system for remote controlled commercial large scale FM transmitters, Energy Conversion and Management, 75, 542-551.

Pasc, P.C. \& Dumitru, C.D. (2016). SCADA system for solar MPPT controller monitoring, Procedia Technology, 23, 803-807.

Saner, H.S. (2015). Türkiye'de güneş enerjisi santrallerinin yer seçimi ve çevresel etkileri: karapınar ve karaman enerji ihtisas endüstri bölgeleri örneklerinin değerlendirilmesi, Yüksek lisans Tezi, Siyaset Bilimi ve Kamu Yönetimi Anabilim Dalı, Ankara Üniversitesi, Ankara, Türkiye.

Shariff, F., Rahim N.A. \& Ping, H.W. (2015). Zigbee-based data acquisition system for online monitoring of grid-connected photovoltaic system, Expert Systems with Applications, 42, 1730-1742.

Zapata, G., Salazar, A., Moreno, D., \& García, R. (2016). Supervision of a Distributed Energy Resources Generation System Using IEC and ISA Standards," IEEE Colombian Conference on Robotics and Automation, Bogota, Colombia..

Zhaoxia, X., Zhijun, G., Guerrero J.M., \& Hongwei, F. (2017). SCADA System for Islanded DC Microgrids. 43rd Annual Conference of the IEEE Industrial Electronics Society, 